\title{
Influence of the thickness of cortical bone on the stability of orthodontic miniscrews
}

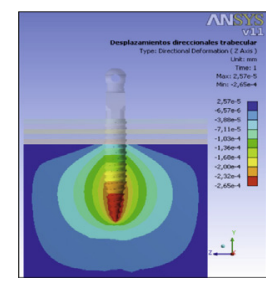

\author{
J. COBO PLANA, F. DE CARLOS VILLAFRANCA, \\ E. MACÍAS ESCALADA, A. ÁLVAREZ SUÁREZ
}

\begin{abstract}
Three 10-mm-long miniscrews commonly employed in orthodontic treatment were compared in four different situations involving diverse thicknesses of cortical bone. The finite element method (FEM) was used in the study, in which a force of $250 \mathrm{~g}$ was applied in two directions: perpendicular and parallel to the bone surface. As the parameter under study was the thickness of cortical bone, simulations were performed in four different bone loss situations: 2.5, 2, 1.5 and $1 \mathrm{~mm}$. Our aim was also to quantify the stresses and displacements generated when applying a force of $250 \mathrm{~g}$ perpendicular and parallel to the bone surface under the same skeletal conditions. The results reveal similar performance in the three analysed samples, with increased stresses and displacements in the surrounding bone in relation to similar variations in the thickness of cortical bone.
\end{abstract}

KEY WORDS

Miniscrews

cortical bone skeletal anchorage

trabecular bone

\section{INTRODUCTION}

Skeletal anchorage systems (mini orthodontic implants [MOI], miniplates, palatal implants, onplants, etc.) have opened up a whole new field, enabling the limitations of traditional anchorage systems to be overcome. $\mathrm{MOI}$ are perhaps the most versatile and most widely used of these devices, providing 'absolute anchorage' in three 
dimensional space in most cases. Furthermore, the ideal skeletal conditions for their placement (1-3), potential locations (4) and biomechanical properties (5) have been studied. Miniscrews may be made of type 5 titanium alloy (the most common), steel or lactic-glycolic. Their diameters range between 1 and 2.5 $\mathrm{mm}$, and their length, although variable, generally ranges between 6 and $12 \mathrm{~mm}$. The choice of the type of miniscrew depends on its placement location, the anatomy of the site and biomechanical requirements. Although the success rate of miniscrews is high (6-8), an appropriate choice of the anatomical site for placement is crucial for a good result $(9,10)$. The main cause of failure is the lack of primary stability due to insufficient thickness of cortical bone (11). However, other factors, such as

\section{MATERIAL AND METHODS}

Three miniscrews measuring $10 \mathrm{~mm}$ in length and $1.6 \mathrm{~mm}$ in diameter were chosen to carry out the comparative study.

These were: Dual top anchor system [Jeil Medical Corporation], IMTEC Ortholmplant [3M Unitek] and Tomas ${ }^{\circledR}$ [Dentaurum].

The stress values generated around a miniscrew when applying a force were studied using the FEM. This method enables a more manageable approximation to the underlying biomechanics than an experimental study.

The miniscrews were first measured using a PERTHOMETER S5P profile projector (Model VB-400, sigma. Madrid [Spain]), subsequently inflammation of the peri-implant tissue, incorrect placement, miniscrew design (thread depth, shape and length of its profile), applied force and direction thereof, among others, may also contribute to their failure (12 -14).

This study aims to evaluate the performance of three types of miniscrews widely used in orthodontic treatment, employing finite element analysis in different situations of thickness of cortical bone. We also aim to quantify the stresses and displacements generated when applying a force of $250 \mathrm{~g}$ in two directions, perpendicular and parallel to the bone surface, under the same skeletal conditions.

generating a 3D model of the $\mathrm{MOI}$. The profile projector allows measurements where normal instruments cannot be used. This means that most of the measurements are of small parts, although the image to project may be 50, 100 or 200 times its original size. Qualitative and quantitative chemical analysis of the elements present was also performed on the $\mathrm{MOI}$ using a CAMECA SX-100 (Electron Probe Micro Analyzer) equipped with five WDS spectrometers.

The results showed that all three miniscrews are made of $90 \%$ titanium, a fact that was taken into ac- 


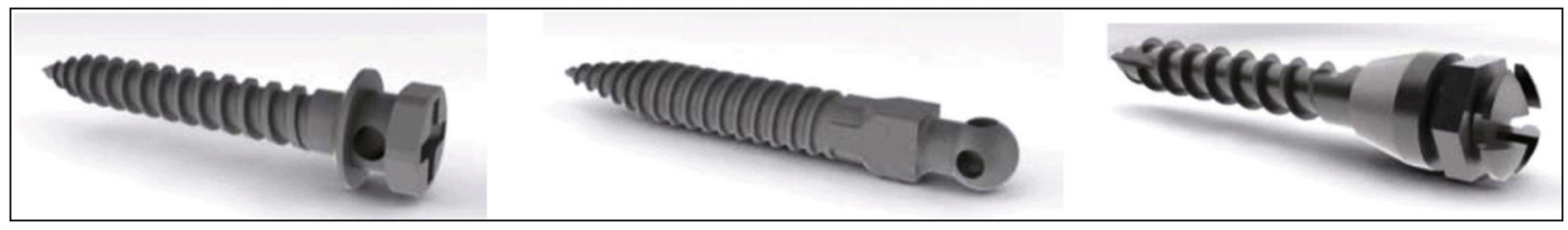

Figure 1

Solidworks design of the Jeil, 3M and Dentaurum miniscrews.

count when assigning physical properties to the MOl.

A previous simulation was performed using finite element analysis (FEA) by means of a simplified $\mathrm{MOI}$ model in two different situations (model 1 [Fig. 2] and model 2 [Fig. 3]). A $1 \mathrm{~mm}$ diameter by $5 \mathrm{~mm}$ length cylinder was used for model 1. A force of $100 \mathrm{~g}$ was applied at the top of the model at a distance of $4 \mathrm{~mm}$ from the cortical bone surface, varying the direction of this force between $0^{\circ}$ (perpendicular to the miniscrew axis), $45^{\circ}$ and $90^{\circ}$ (in the same direction as the axis).

Using the profile projector and microscope data, we generated a 3D model for each miniscrew as similar as possible to the real models (Fig. 1).

Additionally, a geometrically perfect matrix was generated to simulate the cortical and trabecular bone layers measuring $10 \mathrm{~mm} \times 10 \mathrm{~mm}$ in the plane perpendicular to the miniscrew axis, with a thickness of
$20 \mathrm{~mm}$ (in the direction of miniscrew axis). The dimensions of the matrix were kept constant for all studies. Varying the thickness of the cortical bone thickness thus resulted in changes in the thickness of the trabecular bone in order for the same final dimensions of the matrix to be maintained. The simulated thicknesses of cortical bone were $1 \mathrm{~mm}$, $1.5 \mathrm{~mm}, 2 \mathrm{~mm}$ and $2.5 \mathrm{~mm}$.

All the materials in the model were considered homogeneous, isotropic and linearly elastic. The miniscrew was likewise considered to be made of pure titanium due to its high content in this material (90\%), Table I.

Trials were conducted by applying a force of $250 \mathrm{~g}$ parallel and perpendicular to the cortical bone surface.

Twenty-four simulations were performed in all involving 3 miniscrews, 4 thicknesses of cortical bone and 2 directions of applied force.

With the aim of comparing the performance of the miniscrews, the distance between the area where force

\begin{tabular}{|l|l|l|}
\hline & Young's modulus & Poisson's coefficient \\
\hline Titanium alloy & $114 \mathrm{GPa}$ & 0,30 \\
\hline Cortical bone & $14 \mathrm{GPa}$ & 0,30 \\
\hline Trabecular bone & $50 \mathrm{MPa}$ & 0,30 \\
\hline
\end{tabular}

Table 1

Physical properties of the materials. 


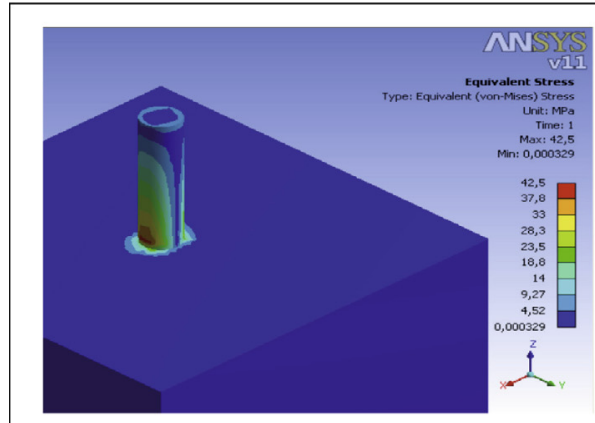

Stress state $\left(0^{\circ}\right)$

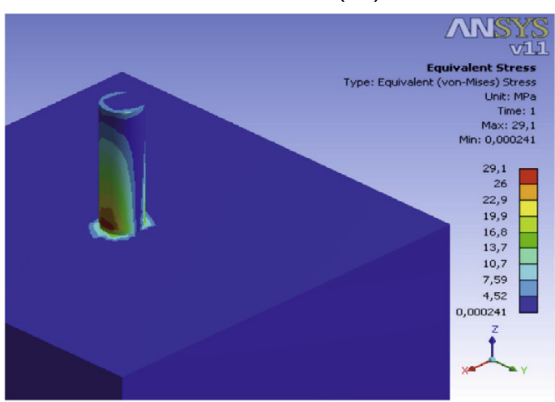

Stress state $\left(45^{\circ}\right)$

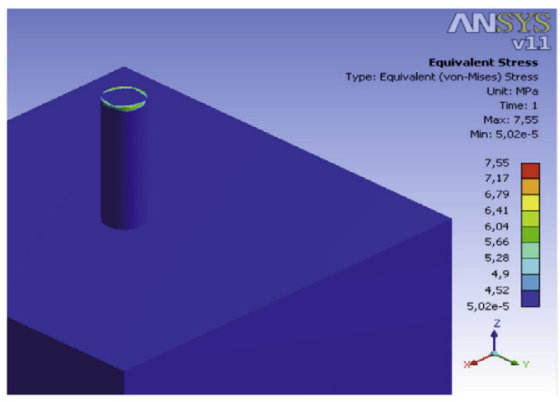

Stress state $\left(90^{\circ}\right)$

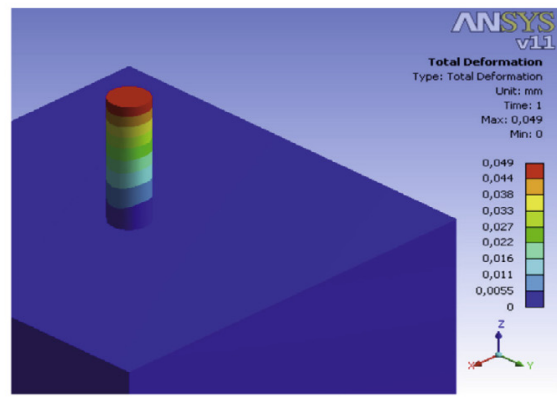

Deformation state $\left(0^{\circ}\right)$

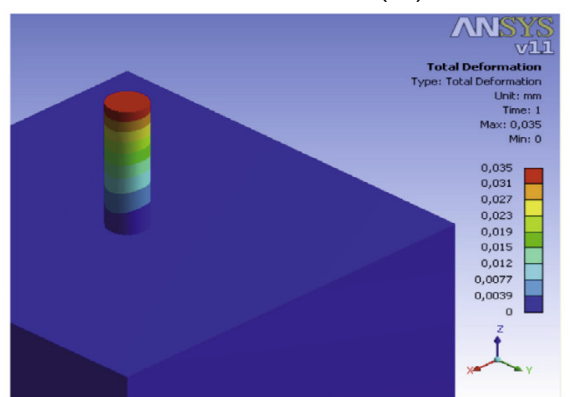

Deformation state $\left(45^{\circ}\right)$

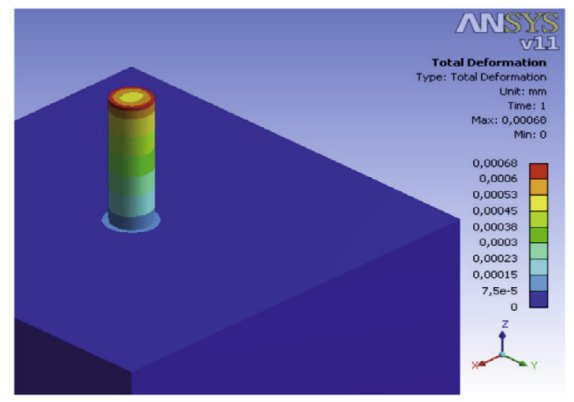

Deformation state $\left(90^{\circ}\right)$
Figure 2

Distribution of displacement and stress values. Model 1. was applied and the outer layer of cortical bone was similar for all three cases. The $3 \mathrm{M}$ miniscrew was taken as the reference measurement, see- ing as it presents the greatest distance between the cylindrical face where force is applied and the end of the thread.

\section{RESULTS}

The following results (Tab. II) were obtained in the simulations carried out using simplified $\mathrm{MOI}$ models:

\begin{tabular}{|l|l|l|l|}
\hline & $\begin{array}{l}\text { Force applied } \\
\text { at } 0^{\circ}\end{array}$ & $\begin{array}{l}\text { Force applied } \\
\text { at } 45^{\circ}\end{array}$ & $\begin{array}{l}\text { Force applied } \\
\text { at } 90^{\circ}\end{array}$ \\
\hline Maximum stress (MPa) & 42,5 & 29,1 & 7,55 \\
\hline Maximum deformation $(\mathrm{mm})$ & 0,05 & 0,035 & 0,0007 \\
\hline
\end{tabular}

Table /I

Results for simplified $\mathrm{MOI}$ model 1. 


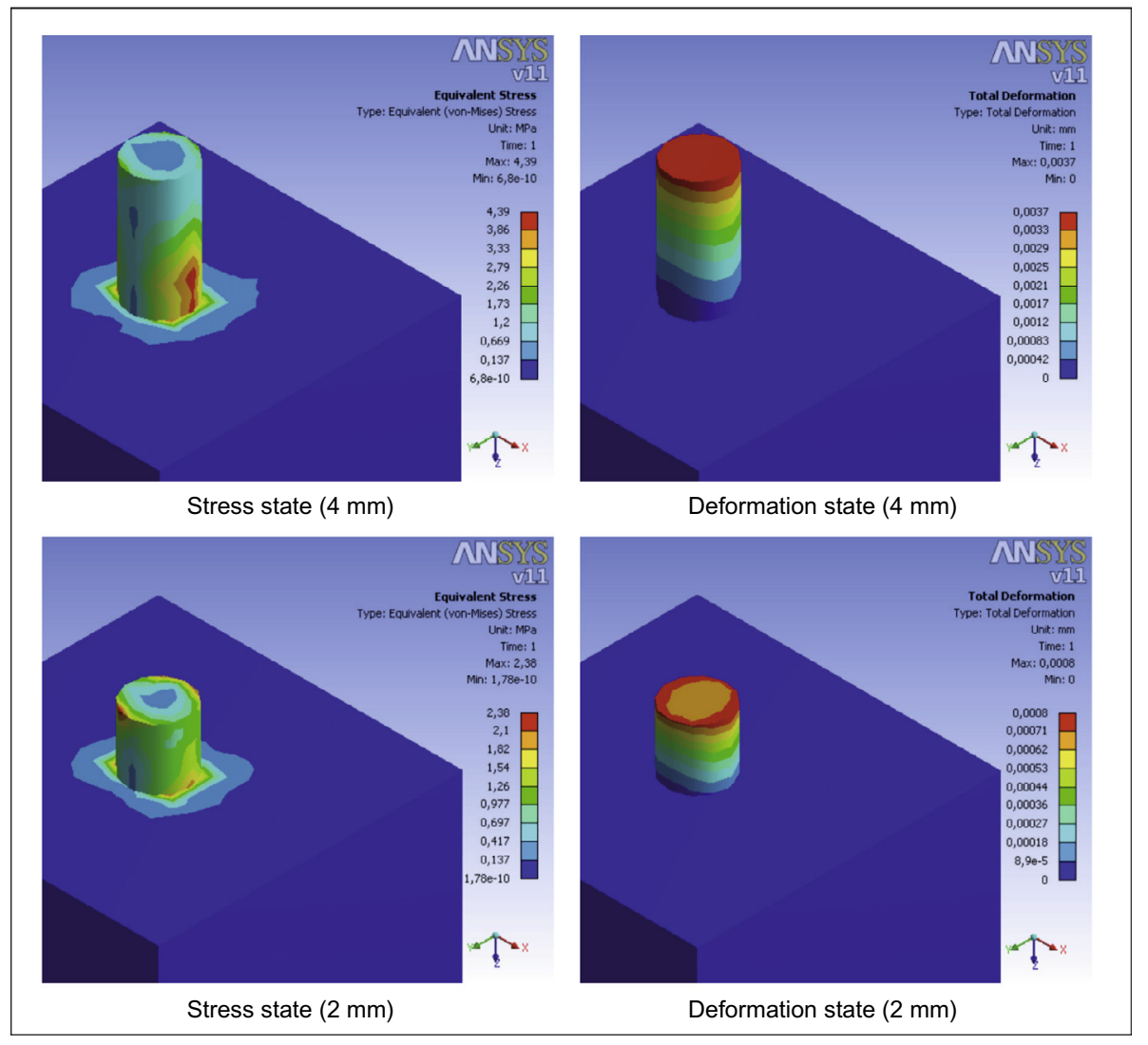

Figure 3

Distribution of displacement and stress values $(2-4 \mathrm{~mm})$. Model 2.

A scale composed of 9 colours was used for the miniscrew as well as for the cortical and trabecular bone in order to evaluate the distribution of the displacement and stress values quantitatively. This scale ranges from blue, indicating the lowest displacement and stress values, to red, indicating the highest.

In model 1 (Fig. 2; $1 \mathrm{~mm}$ diameter by $5 \mathrm{~mm}$ length cylinder), it was observed that both the maximum stress and maximum deformation in the miniscrew increase as the force approaches $0^{\circ}$, as can be seen in Table II.
In model 2 (Fig. 3; 2 mm diameter by $15 \mathrm{~mm}$ length cylinder), three loading conditions are once again proposed, respectively fixing the distance from the point of application of the load at $4 \mathrm{~mm}, 2 \mathrm{~mm}$ and $1 \mathrm{~mm}$ (the distance between the top of the screw and the outer layer of cortical bone). As regards the orientation of the force, $0^{\circ}$ was employed for all three cases, as shown in Table III.

After generating the simplified models, finite elements were used to study the performance of the three micro-implants. The studies consisted in applying a force of $250 \mathrm{~g}$ in 


\begin{tabular}{|l|l|l|l|}
\hline & $\begin{array}{l}\text { Force applied } \\
\text { at } 4 \mathrm{~mm}\end{array}$ & $\begin{array}{l}\text { Force applied } \\
\text { at } 2 \mathrm{~mm}\end{array}$ & $\begin{array}{l}\text { Force applied } \\
\text { at } 1 \mathrm{~mm}\end{array}$ \\
\hline Maximum stress (MPa) & 4,38 & 2,37 & 2,278 \\
\hline Maximum deformation $(\mathrm{mm})$ & 0,0037 & 0,0008 & 0,00028 \\
\hline
\end{tabular}

Table III

Results for simplified $\mathrm{MOI}$ model 2. parallel to the direction of the cortical bone surface (perpendicular to the axis of the implant). As the key parameter under study in this paper is the influence of the thickness of cortical bone, simulations were performed with 4 different cortical bone thicknesses ranging from $1 \mathrm{~mm}$ to $2.5 \mathrm{~mm}$.
The results, shown in Table 4, include the stress state and the displacement in the miniscrew and in both the cortical and trabecular bone in the direction of the applied force, as well as the different thicknesses of cortical bone. The von Mises equivalent stress was taken as the stress state.

\begin{tabular}{|c|c|c|c|c|c|c|c|c|}
\hline & \multicolumn{2}{|c|}{ Implant } & \multicolumn{2}{|c|}{ Cortical bone } & \multicolumn{2}{|c|}{ Trabecular bone } \\
\hline & & & $\begin{array}{l}\text { Stress } \\
\text { (MPa) }\end{array}$ & $\begin{array}{l}\text { Displacement } \\
(\mathrm{mm})\end{array}$ & $\begin{array}{l}\text { Stress } \\
\text { (MPa) }\end{array}$ & $\begin{array}{l}\text { Displacement } \\
(\mathrm{mm})\end{array}$ & $\begin{array}{l}\text { Stress } \\
\text { (MPa) }\end{array}$ & $\begin{array}{l}\text { Displacement } \\
(\mathrm{mm})\end{array}$ \\
\hline \multirow{8}{*}{ 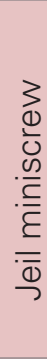 } & \multirow{2}{*}{$2,5 \mathrm{~mm}$} & $F x$ & 31,29 & 4,30E-03 & 11,92 & 3,57E-04 & 0,03 & 1,60 E-04 \\
\hline & & $\mathrm{Fz}$ & 32,04 & $4,26 \mathrm{E}-03$ & 12,75 & 3,94E-04 & 0,03 & 1,59 E-04 \\
\hline & \multirow{2}{*}{$2 \mathrm{~mm}$} & Fx & 31,30 & 4,45E-03 & 12,08 & $3,85 \mathrm{E}-04$ & 0,05 & 2,79 E-04 \\
\hline & & $\mathrm{Fz}$ & 32,06 & $4,41 \mathrm{E}-03$ & 12,93 & 4,23 E-04 & 0,05 & 2,77 E-04 \\
\hline & \multirow{2}{*}{$1,5 \mathrm{~mm}$} & Fx & 31,31 & 4,84E-03 & 12,50 & 4,56 E-04 & 0,08 & 5,06 E-04 \\
\hline & & $\mathrm{Fz}$ & 32,10 & 4,80E-03 & 13,43 & 4,94 E-04 & 0,09 & 5,06 E-04 \\
\hline & \multirow{2}{*}{$1 \mathrm{~mm}$} & Fx & 31,33 & 5,96E-03 & 13,52 & 6,36 E-04 & 0,16 & 1,01 E-03 \\
\hline & & $\mathrm{Fz}$ & 32,21 & $5,90 \mathrm{E}-03$ & 14,57 & 6,94 E-04 & 0,17 & 1,01 E-03 \\
\hline \multirow{8}{*}{$\begin{array}{l}3 \\
\frac{\Phi}{U} \\
\frac{\omega}{E} \\
\frac{E}{E} \\
\sum \\
\sum\end{array}$} & \multirow{2}{*}{$2,5 \mathrm{~mm}$} & Fx & 19,34 & 2,38E-03 & 7,77 & $2,72 \mathrm{E}-04$ & 0,04 & 2,64E-04 \\
\hline & & $\mathrm{Fz}$ & 19,00 & 2,39E-03 & 8,11 & $2,78 \mathrm{E}-04$ & 0,03 & $2,65 \mathrm{E}-04$ \\
\hline & \multirow{2}{*}{$2 \mathrm{~mm}$} & Fx & 19,36 & 2,57E-03 & 7,91 & $3,10 \mathrm{E}-04$ & 0,07 & 4,27E-04 \\
\hline & & $\mathrm{Fz}$ & 18,90 & $2,58 \mathrm{E}-03$ & 8,31 & $3,16 \mathrm{E}-04$ & 0,06 & 4,28E-04 \\
\hline & \multirow{2}{*}{$1,5 \mathrm{~mm}$} & $F x$ & 19,40 & 2,97E-03 & 8,17 & 3,84E-04 & 0,11 & $7,20 \mathrm{E}-04$ \\
\hline & & $\mathrm{Fz}$ & 18,84 & 2,98E-03 & 8,66 & 3,93E-04 & 0,09 & $7,20 \mathrm{E}-04$ \\
\hline & \multirow{2}{*}{$1 \mathrm{~mm}$} & Fx & 19,38 & $3,81 \mathrm{E}-03$ & 8,36 & 5,29E-04 & 0,19 & $1,24 \mathrm{E}-03$ \\
\hline & & $\mathrm{Fz}$ & 18,85 & $3,82 \mathrm{E}-03$ & 8,90 & $5,42 \mathrm{E}-04$ & 0,16 & 1,24E-03 \\
\hline \multirow{8}{*}{ 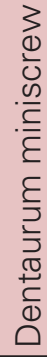 } & \multirow{2}{*}{$2,5 \mathrm{~mm}$} & Fx & 22,20 & $3,13 \mathrm{E}-03$ & 13,83 & 3,83E-04 & 0,05 & 1,31E-04 \\
\hline & & $\mathrm{Fz}$ & 20,05 & 2,90E-03 & 8,43 & 3,83E-04 & 0,05 & 1,31E-04 \\
\hline & \multirow{2}{*}{$2 \mathrm{~mm}$} & $F x$ & 22,20 & 3,34E-03 & 13,99 & 4,22E-04 & 0,08 & 2,38E-04 \\
\hline & & $\mathrm{Fz}$ & 20,05 & $3,11 \mathrm{E}-03$ & 8,59 & 4,22E-04 & 0,08 & $2,34 \mathrm{E}-04$ \\
\hline & \multirow{2}{*}{$1,5 \mathrm{~mm}$} & Fx & 22,19 & 3,87E-03 & 14,40 & $5,13 \mathrm{E}-04$ & 0,14 & 4,61E-04 \\
\hline & & $\mathrm{Fz}$ & 20,04 & 3,64E-03 & 9,06 & 5,17E-04 & 0,14 & 4,55E-04 \\
\hline & \multirow{2}{*}{$1 \mathrm{~mm}$} & Fx & 22,20 & 5,34E-03 & 15,22 & $7,54 \mathrm{E}-04$ & 0,27 & $9,81 \mathrm{E}-04$ \\
\hline & & $\mathrm{Fz}$ & 20,01 & 5,09E-03 & 9,91 & 7,46E-04 & 0,25 & 9,66E-04 \\
\hline
\end{tabular}

Table IV

Comparison of results for the three miniscrews. 
To evaluate the results, we represent the sequence graph of the most significant images of the finite element analysis representing the stresses and displacements in the

\section{DISCUSSION}

A comparison of the performance of three $\mathrm{MOl}$ is made in this study, quantifying and analysing stresses and displacements. In $\mathrm{MOI}$ model 1, Figure 2, when applying a force of $100 \mathrm{~g}$ to the same screw and changing its orientation, both the maximum stress and maximum deformation increased as the force approaches $0^{\circ}$. The stresses were miniscrew (Fig. 4), in the cortical bone (Fig. 5) and in the trabecular bone (Fig. 6) at different thicknesses of cortical bone. lower when the force was applied at $90^{\circ}$ along the main axis of the miniscrew. These results are in line with those obtained by Pickard ${ }^{19}$, who showed that when force is applied along the main axis of the miniscrew, it had greater stability and resistance to failure than in any other situation, resisting maximum forces of up to $342 \mathrm{~N}$. Under these circumstances,

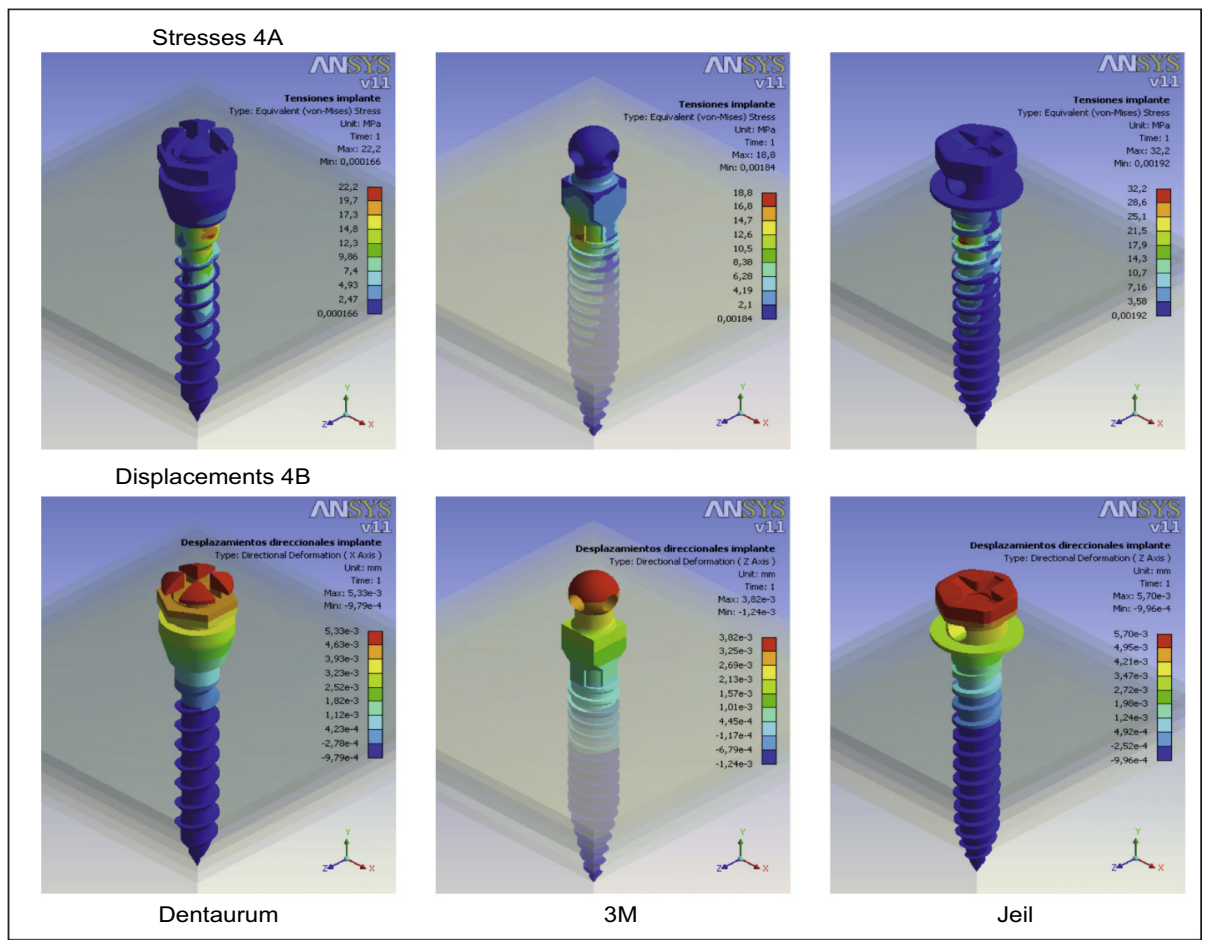

Figure 4

Miniscrew stresses and displacements, $1 \mathrm{~mm}$ thickness cortical bone. 


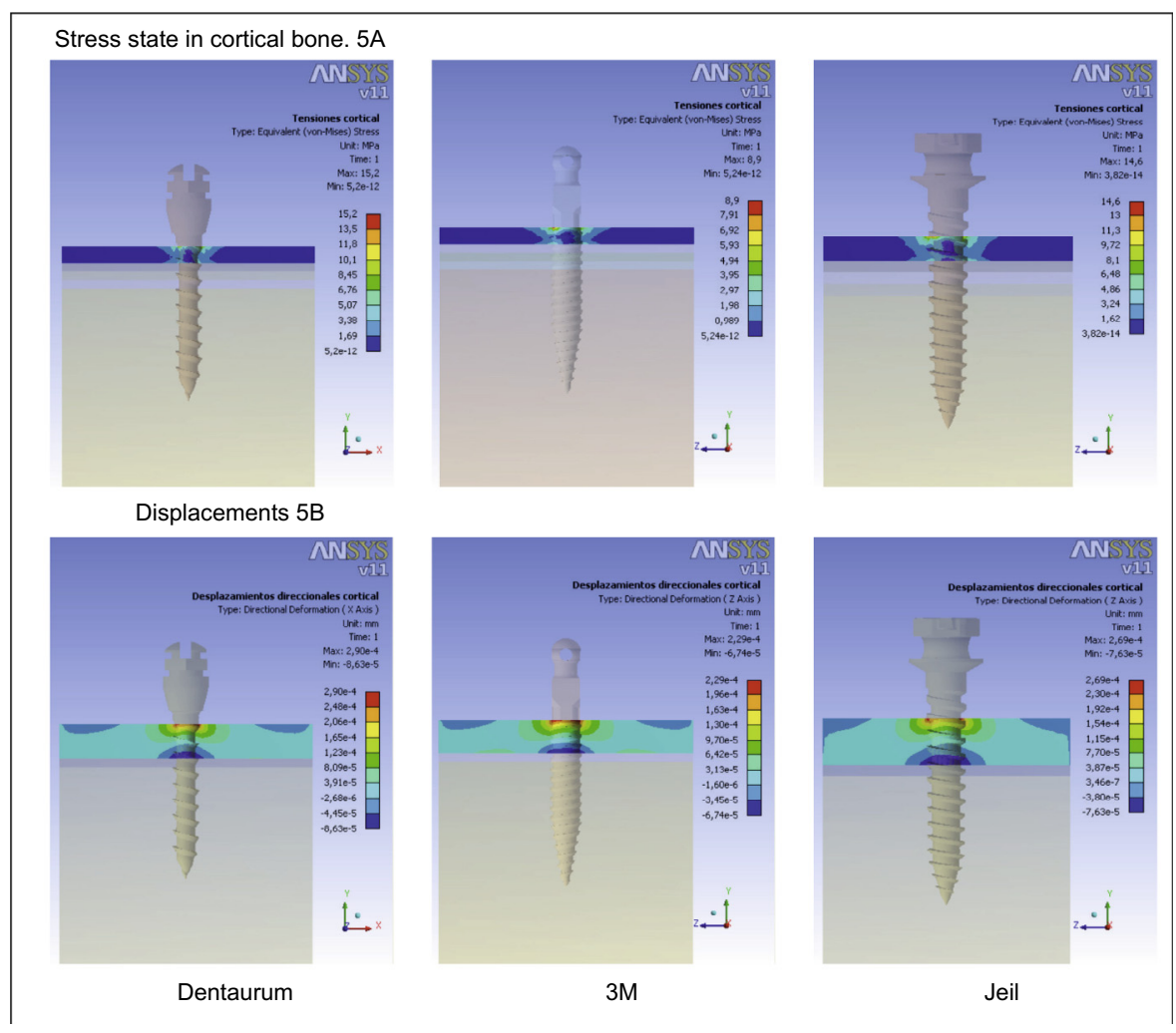

Figure 5

Miniscrew stresses and displacements, $1 \mathrm{~mm}$ thickness cortical bone.

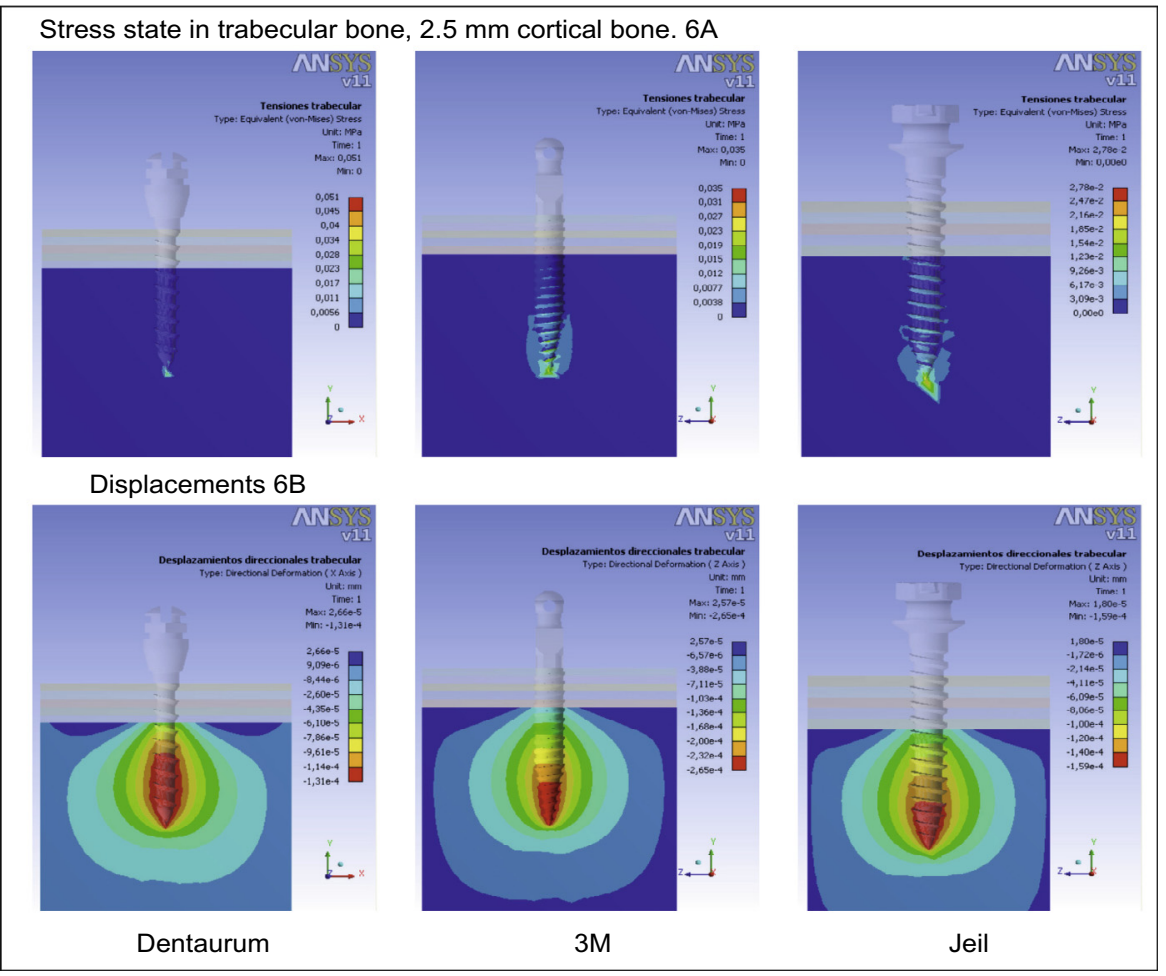

Figure 6

Miniscrew stresses and displacements. 
the thread of the miniscrew is perpendicular to the load, i.e. it is in the optimum position to withstand the applied force. However, if the miniscrew is placed at $45^{\circ}$ in the same direction as the applied force, it has greater stability and resistance to failure than another miniscrew placed at the same angle, but facing in the opposite direction to the application of force. Jasmine et al. ${ }^{9}$ likewise concur that the miniscrew should be placed as perpendicular to the bone as possible to achieve greater stability. However, it is not always possible to place the miniscrew perpendicular to the surface of the bone. The arrangement of the tooth roots or the special anatomy of the chosen area sometimes forces us to modify the main axis of the $\mathrm{MOI}$. Addressing the risk of root injury that placement of a $\mathrm{MOI}$ perpendicular to the bone in the posterior interradicular spaces subsequently involves, Park et al. ${ }^{17}$ suggests placing miniscrews with a distal inclination of $10^{\circ}$ to $20^{\circ}$. Melsen ${ }^{14}$ recommends placing the miniscrews obliquely in the maxilla, in an apical direction, but advocates placing them as parallel as possible to the roots in the interdental spaces in the mandible. Kyung et al. ${ }^{11}$ propose placing them at an angle of $30^{\circ}$ to $40^{\circ}$ to the axis of the tooth in the maxilla and of $10^{\circ}$ to $20^{\circ}$ in the mandible. Carano et al. ${ }^{2}$ suggest an angle of $30^{\circ}$ to $45^{\circ}$ in the maxilla, although they recommend placing the miniscrew in a perpendicular position in areas near the maxillary sinus to prevent damaging it. In our study, the performance of the three screws was very similar. Although the differences between the $3 \mathrm{MOI}$ are minimal, the area of maximum stress is located at the site supporting the base of the head of the 3 miniscrews (Fig. 4A), while the displacement of all three (Fig. 4B) is practically zero at the base. As for load stresses at the cortical bone level (Fig. 5A) and displacements (Fig. 5B), these are very similar, in the order of $2.2-2.9 \times 10^{-4}$. Greater stresses appear in the trabecular bone in the Jeil screw (Fig. 6) under the same load conditions. Therefore, despite the low value of the stresses, this $\mathrm{MOl}$ design would be the one in which the cortical bone supports the highest load (Fig. 6A). As regards displacements, however, the Jeil $\mathrm{MOI}$ shows around $30 \%$ less displacement than the other two designs (Dentaurum and 3M) (Figure 6B).

Chazigianni et al. ${ }^{4}$ concluded that length and diameter are significant parameters in miniscrew stability only when high levels of force are applied. However, Liu et al. ${ }^{13}$ state that the diameter is the dominant factor in the mechanical response of miniscrews. As in the present study, they found that both stress and displacement decrease with increasing thickness of cortical bone. In our results, displacement increases with decreasing thickness of the cortical bone. This may be due to the fact that the miniscrew tends to move more as the thickness of the most rigid layer decreases. The 3M miniscrew, which showed the lowest displacement values in cortical bone, presented the greatest displacements in trabecular bone. This may have been the result of the effect of the miniscrew rotating in the direction of the applied force. The structural differences between cortical bone and trabecular 
bone lead to lower stress in trabecular bone than in cortical bone.

Miniscrew design also varies between different manufacturers and it is difficult to discern which offers the best mechanical properties. In this study, we chose three miniscrews with similar insertion features. We found a higher concentration of stress at the neck of the miniscrew. This is consistent with findings by Singh et al. ${ }^{21}$, who also found, as in this study, that the stress in trabecular bone was minimal. Furthermore, these authors showed that when a lateral force is applied, miniscrews with a smaller neck diameter are more likely to bend or break than those with a larger diameter. This breakage tends to occur in the neck of the miniscrew, where it joins the cortical bone.

In simplified $\mathrm{MOI}$ model 2 employed in this study, it can be seen that both the maximum stress and deformation increase as the point of application of force moves further away. Our results agree with those of Choi et al. ${ }^{5}$, who used a lateral force of $2 \mathrm{~N}$, also reporting that the stress in the adjacent bone increases with the increasing height of the miniscrew head and the point of application of force.

As regards the analysis by means of the finite element model, the variations in the thickness of cortical bone do not affect the maximum stresses recorded on each miniscrew, the Jeil miniscrew being the one showing the highest load, while the $3 \mathrm{M}$ and Dentaurum miniscrews had the lowest values. However, increased stress was observed in both cortical and trabecular bone. Reducing the thickness of the cortical bone layer leads to an increase in the recorded stresses in cortical bone. This increase, which is relatively constant, is due to the fact that the effective cross-section of embedment of the most rigid implant decreases with decreasing thickness of the layer of cortical bone. Reducing the thickness of the cortical bone layer leads to an increase in the recorded stresses in the trabecular area. By decreasing the cross-section of embedment in the most rigid area (cortical bone), the influence of the less rigid area becomes greater, thereby leading to increased stress in trabecular bone.

The 3M miniscrew showed significantly lower maximum stress in cortical bone than the Dentaurum and Jeil miniscrews. The increased stress in trabecular bone increased with decreasing thickness of cortical bone. The 3M miniscrew, which had showed the lowest values of displacement in cortical bone, had the greatest displacements in trabecular bone.

Although the load conditions are very similar, the Jeil screw supports the load better, whereas the $3 \mathrm{M}$ screw withstands displacements better.

The stress in trabecular bone is much lower than that in cortical bone due to differential features of each type of bone.

The design of the $\mathrm{MOl}$ threads influences both the conditions of displacements and stresses. This structure accordingly withstands stresses 
better in some cases (Jeil) while avoiding displacements better in others (3M).

Nonetheless, our study has certain limitations. First, the geometry of the bone block was simplified to that of a rectangular block and the material properties were considered homogeneous. The possible influence of soft peri-implant tissue was not taken into account either.

\section{CONCLUSION}

The three miniscrews studied were perform similarly in this study.

Reduced thickness of cortical bone does not produce an increase in stress in the miniscrews, the stress values remaining constant for different thicknesses.

A reduction in cortical bone leads to increased displacement in the direction of the force vector of the miniscrew, increasing significantly for low cortical bone thicknesses. It also leads to a small increase in maximum stresses in cortical bone and a more significant increase in trabecular bone. Finally, the reduction in cortical bone thickness leads to increased directional displacements into both cortical and trabecular bone.

\section{BIBLIOGRAPHY}

1 Alsamak S, Gkantidis N, Bitsanis E et al. Assessment of potential orthodontic miniimplant insertion sites based on anatomical hard tissue parameters: a sistematic review. In J Oral Maxillofac Implants 2012;27:875-887.

2 Carano A, Velo S, Leone P, Siciliani G. Clinical applications of the Miniscrew Anchorage System. J Clin Orthod 2005;39:9-24.

3 Chang JZ, Chen YJ, Tung YY, Chiang YY, Lai EH, Chen WP, Lin CP. Effects of thread depth, taper shape, and taper length on the mechanical properties of mini-implants. Am J Orthod Dentofacial Orthop 2012;141:279-88.

4 Chatzigianni A, Keilig L, Reimann S, Eliades T, Bouravel C. Effect of mini-implant length and diameter on primary stability under loading with two force levels. Eur J Orthod 2011;33:381-7.

5 Choi B, Lee DO, Mo SS, Kim SH, Park KH, Chung KR, Nelson G, Han SH. Threedimensional finite element analysis for determinig the stress distribution after loading the bone surface with two-component mini-implants of varying length. Korean $\mathrm{J}$ Orthod 2011;41(6):423-430.

6 Floorvaag B, Kneuertz P, Lazar F, et al. Biomechanical properties of orthodontic miniscrews. An in vitro study. J Orofac Orthop 2010;71:53-67.

7 Gracco A, Giagnorio C, Incerti Parenti S et al. Effects of thread shape on the pullout strength of miniscrews. Am J Orthod Dentofacial Orthop 2012;142:186-90.

8 Horner KA, Behrents RG, Kim KB, et al. Cortical bone and ridge thickness of hyperdivergent and hypodivergent adults. Am J Orthod Dentofacial Orthop 2012;142:170-8. 
9 Jasmine MI. M, Yezdani AA, Tajir F, et al. Analysis of stress in bone and micro-implants during en-masse retraction of maxillary and mandibular anterior teeth with different insertion angulations : a 3-dimensional finite element analysis study. Am J Orthod Dentofacial Orthop 2012;141:71-80.

10 Kuroda S, Sugawara Y, Deguchi T, et al. Clinical use of miniscrew implants as orthodontic anchorage: success rates and postoperative discomfort. Am J Orthod Dentofacial Orthop 2007;131:9-15.

11 Kyung HM, Park HS, Bae SM, et al. Development of orthodontic micro-implants for intraoral anchorage. J Clin Orthod 2003;37:321-8.

12 Lim HJ, Choi YJ, Evans CA, Hwang HS. Predictors of initial stability of orthodontic miniscrew implants. Eur J Orthod 2011;33:528-532.

13 Liu TC, Chang CH, Wong TY, and Liu JK. Finite element analysis of miniscrew implants used for orthodontic anchorage. Am J Orthod Dentofacial Orthop 2012;141:468-76.

14 Melsen B. Mini-implants : where are we? J Clin Orthod 2005;39:539-47.

15 Motoyoshi M, Uemura M, Ono A, et al. Factors affecting the long term stability of orthodontic mini-Implants. Am J Orthod Dentofacial Orthop 2010;137:588-593.

16 MotoyoshiM, Yoshida T, Ono A, et al. Effect of bone thickness and implant placement torque on stability of orthodontics mini-Implants. Int J Oral Maxillofac Implants 2007;22:779-78,4.

17 Park HS, Hwangbo ES, Kwon TG. Proper mesiodistal angles for microimplant placement assessed with 3-dimensional computed tomography images. Am J Orthod Dentofacial Orthop 2010;137:200-6.

18 Park HS, Lee YJ, Jeong SH et al. Density of the alveolar and basal bones of the maxilla and mandible. Am J Orthod Dentofacial Orthop 2008;133:30-7.

19 Pickard MB, Dechow P, Rossouw PE, et al. Effects of miniscrew orientation on implant stability and resistance to failure. Am J Orthod Dentofacial Orthop 2010;137:91-9.

20 Reynders R, Ronchi L, Bipat S. Mini-Implants in orthodontics: A systematic review of the literature. Am J Orthod Dentofacial Orthop 2009;135:564-583.

21 Shing S, Mogra S, Shetty VS, Shetty S, Philip P. Three-dimensional finite element analysis of strength, stability, and stress distribution in orthodontic anchorage : A conical, self-drilling miniscrew implant system. Am J Orthod Dentofacial Orthop 2012;141:327-36.

22 Türköz C, Ataç MS, Tuncer $C$, et al. The effect of drill-free and drilling methods on the stability of mini-implants under early orthodontic loading in adolescent patients. Eur $\mathrm{J}$ Orthod 2011;33:533-6. 